\title{
Synthesis and evaluation of aromaticity and tautomerization of pyrazolopyridazin(on)es
}

\author{
NURETTIN MENGES* and İSHAK BİLDİRİĊ \\ Faculty of Pharmacy, Pharmaceutical Chemistry Section, Yuzuncu Yil University, 65090 Van, Turkey \\ E-mail: nurettinmenges@yyu.edu.tr
}

MS received 4 August 2016; revised 27 March 2017; accepted 24 April 2017

\begin{abstract}
Aromaticity of pyrazolopyridazin(on)es was investigated using NICS(0), NICS(1), NICSzz(1), FIPC-NICS and HOMA aromaticity indexes and it was observed that aromaticity of pyridazin(on)es was amenable to aromaticity of pyrazole and vice versa. Some tautomeric forms of pyridazinone were analyzed and the localized orbital locator maps, electron density maps, Fuzzy, Laplacian, and Mayer bond order methods showed dominant form. Different substituents, amine, chlorine, phenyl, methyl, hydrogen, substituted-phenyl, etc. on both the rings were chosen to search out the substituent effect. Aromaticity of pyrazolopyridazin(on)es was searched out in detail for the first time.
\end{abstract}

Keywords. NICS; FIPC-NICS; Keto-enol tautomer; bond order; LOL map.

\section{Introduction}

Pyrazolopyridazin(on)e is a bicyclic nitrogen-containing structure and one of the important core of heterocyclic compounds (Figure 1). Their derivatives are applied as ligand for hedge hog signal cascade, ${ }^{1}$ used for treatment of neuropathic pain ${ }^{2}$ and as antinociceptive agents. ${ }^{3}$ In addition to important biological activities, pyrazolopyridazin(on)es have interesting electronic properties, ${ }^{4}$ but there is no investigation focused on revealing computation-based aromatic and electronic parameters of this skeleton in detail yet.

Aromaticity is an important concept in physical organic chemistry. ${ }^{5 a-c, 7,8,13-15}$ It has been very useful in the rationalization of the structure, stability and reactivity of many molecules. Aromaticity is not an observable quantity and it is defined by convention. It has a broad area of usage in almost all disciplines of chemistry. The aromaticity is a significant concept to be used in the rationalization of chemical reactivity and, by extension, in the understanding of biological properties. In hetero-aromatic chemistry, the degree of aromaticity has a particular importance in guiding our understanding of molecules. ${ }^{6,9}$

Magnetic indices of aromaticity are based on the $\pi$ electron ring current induced when the system is exposed to external magnetic fields. There is a wellknown probe used to measure aromaticity, namely, harmonic oscillator model of aromaticity (HOMA). ${ }^{5 \mathrm{~d}-\mathrm{f}}$

\footnotetext{
*For correspondence
}

More recently, a new and widely used aromaticity index, the nucleus-independent chemical shift (NICS), has been proposed by Schleyer et al. ${ }^{11}$ It has been reported that the negative value of the absolute shielding was observed at a ring center or at some other interesting points of the system. Rings with large negative NICS values indicate strong aromatic character. On the other hand, aromaticity will increase when the value of HOMA gets closer to 1 and a value of HOMA smaller than 0.5 means that the molecule is either antiaromatic or nonaromatic. The more negative the NICS values are, the more aromatic are the rings. These measurement techniques are important for any desired ring in polycyclic aromatic molecules. There are many NICS variants such as NICSzz and NICS(0), NICS(1) to be calculated for aromaticity of the rings. Lastly, free of in-plane component NICS (FIPC-NICS) was explored by Tiznado et al. ${ }^{10}$ FIPC-NICS can be found by calculating of NICS at a point above the molecular plane where the inplane component decays to zero, giving indication that the local contributions to the induced magnetic fields at this point can be omitted. This research uncovered that there are some discrepancies from different NICS components. ${ }^{10}$ FIPC-NICS approximation was therefore picked out.

The aim of this study is to search out the substituentdependent aromaticity and tautomerization of pyrazolopyridazin(on)es by means of NICS(0), NICS(1), NICSzz(1), FIPC-NICS and HOMA. As a continuation of our interest on heterocyclic systems, especially the formation of pyrazoles and pyrazolopyridazines, we 


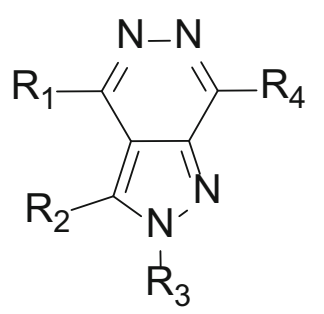

Figure 1. General view of pyrazolopyridazine unit.

have calculated some parameters of NICS to answer the question: how the magnetic shieldings can be altered via different types of substituents and which component of NICS is more accurate.

\section{Experimental}

\subsection{Method and materials}

Geometric optimizations were performed by using Gaussian $09^{12 \mathrm{a}}$ through Gaussview 5.0.9. and by the method of B3LYP/6-311 G(d,p). ${ }^{12 b-d}$ Absolute values of NMR shielding were calculated by using the Gauge-independent Atomic Orbital method with the restricted closed shell formalism employing 6-311G(d,p) basis set over B3LYP/6-311G(d,p) optimized geometries. ${ }^{12 b, 16}$ NICS values were obtained by calculating absolute NMR shielding at different points of the rings NICS(0), NICS(1) and NICS(1.5). Calculation of bond orders, electron density and localized orbital locator (LOL) maps and plotting of maps were done by using Multiwfn suit software. ${ }^{17,18}$ The normal mode analyses for each structure have yielded no imaginary frequencies for the $3 \mathrm{~N}-6$ vibrational degrees of freedom, where $\mathrm{N}$ is the number of atoms in the system, which indicates that the structure of each molecule corresponds to at least one local minimum on the potential energy surface.

Solvents were dried by refluxing with the appropriate dessicants (sodium with ketyl for diethylether, $\mathrm{CaCl}_{2}$ or $\mathrm{Na}_{2} \mathrm{SO}_{4}$ for benzene, toluene, etc.) and distilled. Melting points were determined on an electrothermal Gallenkamp apparatus and are uncorrected. The IR spectra were obtained using a BioRad 130 FT-IR spectrometer with ATR mode. The ${ }^{1} \mathrm{H}$ - and ${ }^{13} \mathrm{C}$-NMR spectra were recorded on Bruker $(300$ and $75 \mathrm{MHz}$, respectively) spectrometers using TMS as an internal standard. All experiments were followed by TLC using a DC Alufolien Kieselgel 60 F 254 Merck and Camag TLC lamp (254/366 nm).

\subsection{General procedure for synthesis}

Compound $\mathbf{2}(\mathbf{2 b}, \mathbf{2 c}$ or $\mathbf{2 i})$ were synthesized by the reported procedure. ${ }^{21}$ Compound $\mathbf{2}(\mathbf{2 b}, \mathbf{2 c}$ or $\mathbf{2 i})(1 \mathrm{mmol})$ was dissolved in excess $\mathrm{SOCl}_{2}(10 \mathrm{mmol})$ and the solution was heated at $70^{\circ} \mathrm{C}$ for $5 \mathrm{~h}$. Then, excess of $\mathrm{SOCl}_{2}$ was evaporated and the residue was washed with dried diethyl ether three times
( $3 \times 15 \mathrm{~mL}$ ). The formed precipitate was filtered. $1 \mathrm{mmol}$ of crude product (acyl chloride) was reacted with appropriate nucleophile (1 mmol) (for $\mathbf{2 d}$ : methyl urea; for $\mathbf{2 f}$ : amonia $(27 \%)$; for $\mathbf{2 g}: \mathbf{M e O H}$; for $\mathbf{2 h}: \mathrm{MeOH})$ at reflux temperature in xylene $(5 \mathrm{~mL})$ for $5 \mathrm{~h}$. Then, solvent was evaporated and the crude product was crystallized from ethanol.

\section{2a N-(methylcarbamoyl)-4-(7-oxo-3,4-diphenyl-6,}

7-dihydro-2H-pyrazolo[3,4-d]pyridazin-2-yl)benzamide (2d): Total yield of two steps: 0.20 g, 51\%; M.p.: 255$256^{\circ} \mathrm{C}$; FT-IR (ATR) $v_{\max } / \mathrm{cm}^{-1}: 3444,3326,3274,3108$, 3066, 2946, 1686, 1652, 1604, 1556, 1527, 1487, 1449, 1410, 1383, 1348, 1305, 1278; ${ }^{1} \mathrm{H}-\mathrm{NMR}(300 \mathrm{MHz}$; DMSO-d 6 ): $\delta$ 13.16 (bs, 1H, NH), 10.85 (bs, 1H, NH), 8.54 (qt, $J=4.0$ $\mathrm{Hz}, \mathrm{NH}, 1 \mathrm{H}$ ) 8.14-8.11 (m, AA'part of AA'BB' system, 2H), 7.95-7.92 (m, BB'part of AA'BB' system, 2H), 7.27-7.11 (m, $\mathrm{ArH}, 10 \mathrm{H}), 2.80$ (d, $J=4.0 \mathrm{~Hz}, 3 \mathrm{H}, \mathrm{Me}) ;{ }^{13} \mathrm{C}-\mathrm{NMR}(75 \mathrm{MHz}$, DMSO-d $\left.{ }_{6}\right): \delta 167.7,154.2,153.3,148.8,143.7,141.9,135.0$, 133.6, 132.7, 131.3, 129.8, 129.2, 129.1, 129.0, 128.9, 128.2, 128.1, 125.9, 118.9, 26.7; Anal. Calcd. for: $\mathrm{C}_{26} \mathrm{H}_{20} \mathrm{~N}_{6} \mathrm{O}_{3}$ : C, 67.23; H, 4.34; N, 18.09\%; Found: C, 67.21; H, 4.33; N, $18.10 \%$.

\section{$2.2 \mathrm{~b}$ 4-(6-methyl-7-oxo-3,4-diphenyl-6,7-dihydro-2} H-pyrazolo[3,4-d]pyridazin-2-yl)benzamide(2f): Total yield of two steps: $0.19,57 \%$; M.p.: $217^{\circ} \mathrm{C}$; FT-IR (ATR) $\nu_{\max } / \mathrm{cm}^{-1}: 3473,3398,3178,3065,1659,1606,1580,1560$, 1531, 1510, 1490, 1468, 1447; ${ }^{1} \mathrm{H}-\mathrm{NMR}$ (300 MHz; DMSO$\mathrm{d}_{6}$ ): $\delta 8.09$ (bs, 1H, NH), 7.89-7.86 (m, AA'part of AA'BB' system, 2H), 7.45-7.42 (m, BB'part of AA'BB' system, $2 \mathrm{H}$ ), 7.34 (bs, ${ }^{1} \mathrm{H}, \mathrm{NH}$ ), 7.27-6.96 (m, ArH, 10H), 3.79 (s, OMe, $3 \mathrm{H}) ;{ }^{13} \mathrm{C}-\mathrm{NMR}(75 \mathrm{MHz}$, DMSO-d 6 ): $\delta$ 167.2, 155.5, 143.5, 142.5, 141.3, 141.0, 135.1, 134.2, 131.0, 129.6, 128.9, 128.8, 128.7, 128.4, 127.9, 126.6, 117.0, 40.7 Anal. Calcd. for: $\mathrm{C}_{25} \mathrm{H}_{19} \mathrm{~N}_{5} \mathrm{O}_{2}$ : C, $71.25 ; \mathrm{H}, 4.54 ; \mathrm{N}, 16.62 \%$; Found: C, 71.27; $\mathrm{H}, 4.55 ; \mathrm{N}, 16.71 \%$.

2.2c Methyl 4-(6-methyl-7-oxo-3,4-diphenyl-6,7-dihydro-2H-pyrazolo[3,4-d]pyridazin-2-yl)benzoate (2g): Total yield of two steps: $0.18 \mathrm{~g}, 60 \%$; M.p.: $188^{\circ} \mathrm{C}$; FT-IR (ATR) $\nu_{\max } / \mathrm{cm}^{-1}: 3058,2951,1723,1675,1605,1580$, 1542, 1520, 1495, 1436; ${ }^{1} \mathrm{H}-\mathrm{NMR}(300 \mathrm{MHz}$; DMSO-d 6 ): $\delta$ 8.25-8.22 (m, AA'part of AA'BB' system, 2H), 7.95-7.92 (m, BB'part of AA'BB' system, 2H), 7.32-7.01 (m, ArH, $10 \mathrm{H}), 3.92$ (s, OMe, $3 \mathrm{H}) ;{ }^{13} \mathrm{C}-\mathrm{NMR}\left(75 \mathrm{MHz}, \mathrm{DMSO}-\mathrm{d}_{6}\right): \delta$ 167.1, 155.1, 142.5, 141.5, 140.1, 140.0, 135.0, 133.2, 130.1, 129.6, 127.7, 127.5, 127.3, 127.1, 126.6, 125.3, 117.05, 52.3, 39.3; Anal. Calcd. for: $\mathrm{C}_{26} \mathrm{H}_{20} \mathrm{~N}_{4} \mathrm{O}_{3}$ : C, 71.55; H, 4.62; N, $12.84 \%$; Found: C, 71.56; H, 4.60; N, 12.84\%.

2.2d Methyl4-(7-oxo-3,4,6-triphenyl-6,7-dihydro-2Hpyrazolo[3,4-d]pyridazin-2-yl)benzoate (2h): Total yield of two steps: $0.22 \mathrm{~g}, 63 \%$; M.p.: $222^{\circ} \mathrm{C}$; FT-IR (ATR) $\nu_{\max } / \mathrm{cm}^{-1}: 3065,2991,2947,1719,1687,1607,1543,1521$, 1492, $1452 ;{ }^{1} \mathrm{H}-\mathrm{NMR}\left(300 \mathrm{MHz}\right.$; DMSO-d $\left.{ }_{6}\right): \delta 8.15-8.13$ (m, AA'part of AA'BB' system, 2H), 8.01-7.99 (m, BB'part of AA'BB' system, 2H), $7.68(\mathrm{~d}, J=9.1 \mathrm{~Hz}, 2 \mathrm{H}), 7.53(\mathrm{t}, J=7.1$ 
$\mathrm{Hz}, 2 \mathrm{H}), 7.45(\mathrm{t}, J=6.8 \mathrm{~Hz}, 2 \mathrm{H}), 7.34-7.14(\mathrm{~m}, \mathrm{ArH}, 9 \mathrm{H})$, $3.92(\mathrm{~s}, \mathrm{OMe}, 3 \mathrm{H}) ;{ }^{13} \mathrm{C}-\mathrm{NMR}\left(75 \mathrm{MHz}, \mathrm{DMSO}-\mathrm{d}_{6}\right): \delta 166.1$, $152.1,148.8,143.6,142.4,141.8,134.5,134.0,131.1,129.8$, $129.4,129.3,129.1,128.4,128.3,128.2,126.9,126.6,118.5$, 52.9; Anal. Calcd. for: $\mathrm{C}_{31} \mathrm{H}_{22} \mathrm{~N}_{4} \mathrm{O}_{3}$ : C, 74.69; $\mathrm{H}, 4.45 ; \mathrm{N}$, 11.24\%; Found: C, 74.71; H, 4.39; N, 11.23\%.

2.2e 4-(7-oxo-3,4,6-triphenyl-6,7-dihydro-2H-pyrazolo[3,4-d]pyridazin-2-yl)benzoyl chloride (2k): Yield: 0.15 g, 67\%; M.p.: $231^{\circ} \mathrm{C}$; FT-IR (ATR) $\nu_{\max } / \mathrm{cm}^{-1}$ : 3062 , 1773, 1734, 1680, 1599, 1538, 1511, 1491, 1444, 1410, 1382, 1355; ${ }^{1} \mathrm{H}-\mathrm{NMR}$ (300 MHz; DMSO-d $\left.{ }_{6}\right): \delta 8.10-8.07$ (m, AA'part of AA'BB' system, 2H), 7.94-7.91 (m, BB'part of AA'BB' system, 2H), $7.64(\mathrm{~d}, J=7.6 \mathrm{~Hz}, 2 \mathrm{H}), 7.49$ (t, $J=7.2$ $\mathrm{Hz}, 2 \mathrm{H}), 7.40$ (t, $J=7.2 \mathrm{~Hz}, 1 \mathrm{H}), 7.30-7.10(\mathrm{~m}, \mathrm{ArH}, 10 \mathrm{H})$; ${ }^{13} \mathrm{C}-\mathrm{NMR}\left(75 \mathrm{MHz}, \mathrm{DMSO}-\mathrm{d}_{6}\right): \delta 167.1,152.1,148.7,142.1$, 141.7, 134.5, 134.0, 131.1, 130.0, 129.8, 129.3, 129.1, 129.0, 128.4, 128.3, 128.2, 126.9, 126.4, 118.4; Anal. Calcd. for: $\mathrm{C}_{30} \mathrm{H}_{19} \mathrm{ClN}_{4} \mathrm{O}_{2}$ : C, 71.64; H, 3.81; N, 11.14\%; Found: C, $71.65 ; \mathrm{H}, 3.83 ; \mathrm{N}, 11.16 \%$.

\section{Results and Discussion}

\subsection{Aromaticity of pyrazolopyridazinones}

In the inital study, we have selected many different substitutent on pyrazolopyridazinone to calculate their aromaticity (Figure 2).

Katritzky and co-workers recommended the use of more than one aromaticity parameter for comparisons restricted to some regions or groups among relatively similar compounds. ${ }^{22}$ In addition, a local index of aromaticity is perhaps more suitable than a global index for the whole molecule when the aromaticity of large polycyclic aromatic hydrocarbon is being studied. NICS components and HOMA values have advantages and provide a local criterion for each ring in a polycyclic system. So, NICS(0), NICS(1), NICSzz(1) and FIPC-NICS have been selected in order to compare aromaticity of pyrazolopyridazinones (Table 1). NICS is a magnetic index and deals with the magnetic shielding of the ring. However, HOMA is a structural index and deals with the planarity of aromatic ring. ${ }^{5 \mathrm{~g}}$

HOMA index measures bond lengths and makes a prediction about aromaticity. If HOMA value equals to 1 , it can be said that all bonds in the calculated system are nearly same. Decrease of HOMA value from 1 to 0 means bond length alternation. With this respect, we have discussed aromaticity of the bicyclic molecules.

HOMA values for pyrazolopyridazinones are within a range of $0.3489-0.4508$ for pyridazinones unit and within $0.7288-0.8898$ for pyrazole unit. The highest HOMA value of pyridazinone is belonging to $\mathbf{2 f}, 0.4508$. One of the nitrogen atom of the ring shares its lone pair electrons to the ring and makes the pyridazinone structurally more favorable. Comparing differents groups attached to nitrogen atom, such as phenyl and hydrogen, gave valuable information about aromaticity of the structure. When methyl group was changed with phenyl (Table 1, 2i), HOMA value of $\mathbf{2 i}$ was found to be 0.3898 , and attaching of the phenyl ring with nitrogen group decreased HOMA. In addition, when methyl group was changed with hydrogen (Table 1, 2c), HOMA value decreased again but less decrease than 2i. We have assumed that the lone pair of the nitrogen adjacent to the carbonyl group affects delocalization and bond lengths. On the other hand, carboxylic acid group attached to the para position of the phenyl ring in pyridazinone ring of $\mathbf{2 a}$ (Table 1) reduced the HOMA more than unsubstituted phenyl ring in $\mathbf{2 i}$. However, chlorine atoms attached to the phenyl ring (Table 1, 2j) increased HOMA value from 0.3898 to 0.4066 when compared with $\mathbf{2 i}$. More electron density on nitrogen gives more delocalization character resulting in more favorable structure which is responsible for the increase of HOMA value. Phenyl ring is electron withdrawing group and methyl group is electron

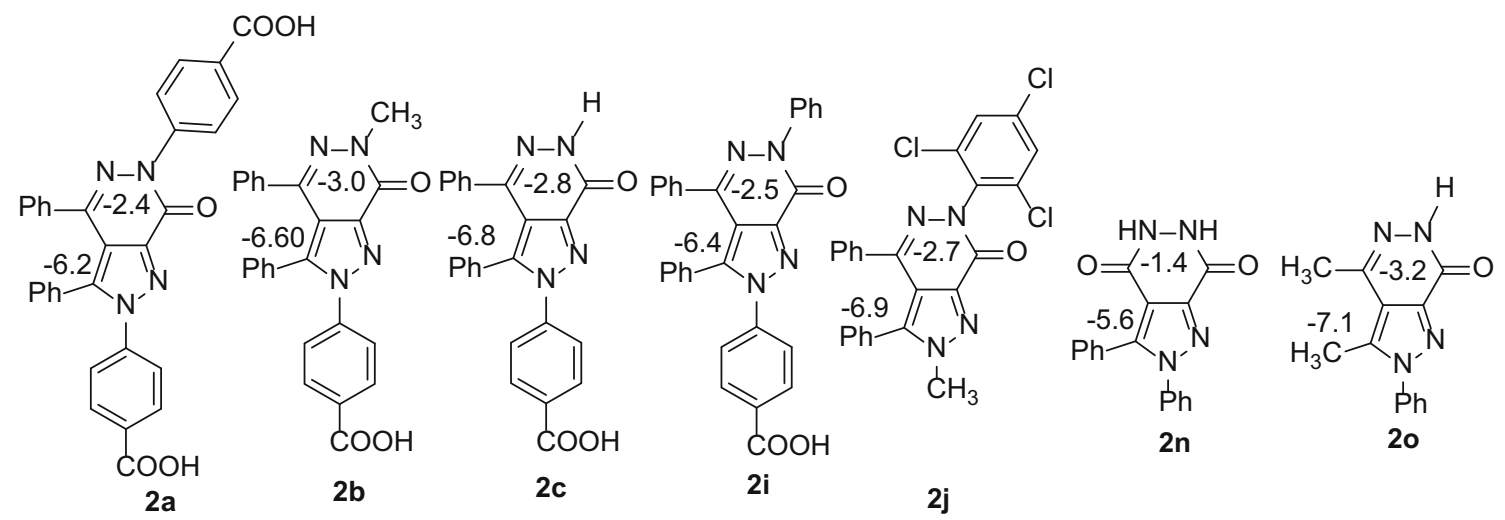

Figure 2. Pyrazolopyridazinone compounds. The values refer to FIPC-NICS. 
Table 1. Aromaticity of compounds with different components of NICS ${ }^{\mathrm{a}}$ and HOMA.

\begin{tabular}{|c|c|c|c|c|c|}
\hline Compound & $\operatorname{NICS}(0)$ & $\operatorname{NICS}(1)$ & $\operatorname{NICSzz}(1)$ & FIPC-NICS & HOMA \\
\hline 2a(pyridazine) & -0.6 & -2.6 & 15.1 & -2.4 & 0.3489 \\
\hline $2 \mathrm{a}($ pyrazole $)$ & -11.3 & -9.3 & -4.9 & -6.2 & 0.7288 \\
\hline 2b(pyridazine) & -1.7 & -3.7 & 12.8 & -3.0 & 0.4466 \\
\hline 2b(pyrazole) & -12.2 & -9.8 & -6.5 & -6.6 & 0.8508 \\
\hline 2c(pyridazine) & -1.2 & -3.1 & 11.7 & -2.8 & 0.4153 \\
\hline $2 \mathrm{c}($ pyrazole $)$ & -12.1 & -10.2 & -7.1 & -6.8 & 0.8424 \\
\hline 2d(pyridazine) & -1.1 & -3.2 & 13.4 & -2.8 & 0.4170 \\
\hline 2d(pyrazole) & -12.3 & -10.9 & -7.76 & -7.4 & 0.8440 \\
\hline 2e(pyridazine) & -4.6 & -7.2 & 1.0 & -5.3 & 0.7036 \\
\hline 2e(pyrazole) & -13.1 & -11.0 & -10.4 & -7.5 & 0.8418 \\
\hline 2f(pyridazine) & -1.6 & -3.5 & 10.0 & -3.0 & 0.4508 \\
\hline $2 \mathrm{f}($ pyrazole $)$ & -11.6 & -10.4 & -8.1 & -6.6 & 0.8551 \\
\hline $2 \mathrm{~g}$ (pyridazine $)$ & -1.8 & -3.1 & 8.7 & -2.3 & 0.4494 \\
\hline $2 \mathrm{~g}$ (pyrazole) & -12.1 & -10.9 & -7.6 & -6.6 & 0.8543 \\
\hline $2 \mathrm{~h}$ (pyridazine) & -0.7 & -2.8 & 15.9 & -2.5 & 0.3930 \\
\hline 2h(pyrazole) & -12.0 & -9.8 & -6.8 & -6.6 & 0.8660 \\
\hline 2i(pyridazine) & -0.8 & -2.8 & 16.0 & -2.5 & 0.3898 \\
\hline 2i(pyrazole) & -11.6 & -9.6 & -5.4 & -6.4 & 0.8624 \\
\hline $2 \mathrm{j}$ (pyridazine) & -1.4 & -3.1 & 11.9 & -2.7 & 0.4066 \\
\hline $2 \mathrm{j}($ pyrazole $)$ & -12.9 & -10.7 & -9.5 & -6.9 & 0.8898 \\
\hline $2 \mathrm{k}$ (pyridazine) & -0.7 & -2.7 & 15.0 & -2.5 & 0.3847 \\
\hline 2k(pyrazole) & -11.5 & -9.6 & -5.3 & -6.4 & 0.8577 \\
\hline 21(pyridazine) & -4.5 & -7.9 & 2.4 & -4.9 & 0.7385 \\
\hline 21(pyrazole) & -13.3 & -12.5 & -10.8 & -8.0 & 0.8812 \\
\hline 2m(pyridazine) & -4.2 & -5.9 & 4.1 & -4.5 & 0.6963 \\
\hline 2m(pyrazole) & -13.0 & -10.1 & -8.0 & -6.9 & 0.8704 \\
\hline 2n(pyridazine) & -0.9 & -0.9 & 18.7 & -1.4 & 0.0780 \\
\hline 2n(pyrazole) & -11.9 & -8.6 & -5.6 & -5.6 & 0.8724 \\
\hline 2o(pyridazine) & -1.9 & -3.7 & 10.9 & -3.2 & 0.4327 \\
\hline 2o(pyrazole) & -12.5 & -10.8 & -7.6 & -7.1 & 0.8596 \\
\hline $2 \mathrm{p}$ (pyridazine $)$ & -0.1 & -0.5 & 22.90 & -1.0 & -0.099 \\
\hline $2 \mathrm{p}($ pyrazole $)$ & -11.3 & -10.7 & -6.9 & -5.6 & 0.8780 \\
\hline $2 \mathrm{r}$ (pyridazine) & -3.7 & -7.4 & 1.4 & -5.6 & 0.7307 \\
\hline 2r(pyrazole) & -13.1 & -11.2 & -11.2 & -7.7 & 0.8348 \\
\hline 2 s(pyridazine) & -5.4 & -8.6 & -5.7 & -6.8 & 0.7740 \\
\hline 2 s(pyrazole) & -14.0 & -11.1 & -12.9 & -7.5 & 0.8610 \\
\hline
\end{tabular}

a: values are in ppm.

donating group. These differences might have an effect on HOMA value. The lowest HOMA value belongs to 2n in which two carbonyl groups are attached to the $\mathrm{NH}$ groups. Absence of any double bond in the pyridazinone ring ends up in decrease of HOMA value. When carboxylic acid group of para position of phenyl ring which is attached to pyrazole was altered with its derivatives such as amide $\mathbf{2 f}$, ester $\mathbf{2} \mathbf{g}$ and $\mathbf{2 h}$, and urea 2d, it was seen that HOMA values have increased slightly.

From Table 1, it can be clearly seen that there are significant discrepancies among aromaticity assignments from different approximations of NICS. For instance, NICSzz(1) values describe that many pyridazine rings as highly antiaromatic whereas NICS(0) and NICS(1) classify them as slightly aromatic. To find out the more accurate NICS component, we have compared all the values. Finally, FIPC-NICS values are found to be the most accurate NICS component for pyrazolopyridazinones. So, we have discussed aromaticities of both rings by means of FIPC-NICS. Then, we have calculated local aromaticity of both rings of pyrazolopyridazinones with different groups to test effect of substituents. Aromaticities of pyridazinone and pyrazole rings of $\mathbf{2 a}$ were -2.4 and $-6.2 \mathrm{ppm}$, whereas, aromaticities of both rings of $2 \mathbf{i}$ were -2.5 (pyridazinone) and -6.4 (pyrazole) ppm, respectively. Carboxylic acid group on phenyl ring has no effect on aromaticity of both 


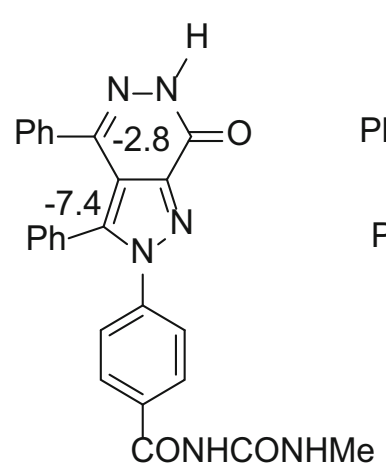

2d

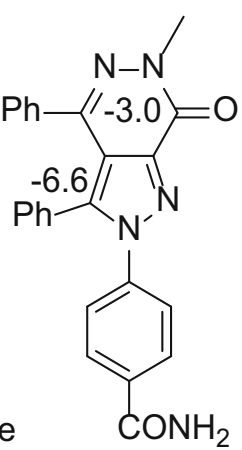

$2 f$

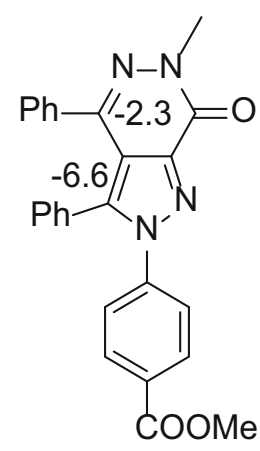

$2 \mathrm{~g}$

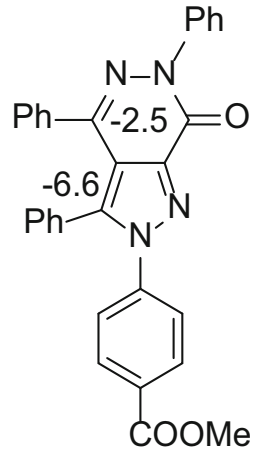

$2 \mathrm{~h}$

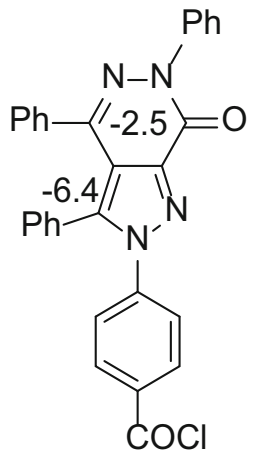

2k

Figure 3. Some new types of pyrazolopyridazinones. The values refer to FIPC-NICS; upper numbers indicate the aromaticity of pyridazine and lower numbers indicate the aromaticity of pyrazole.

rings. It can be said that there is no change on magnetic shielding if benzene ring has electron withdrawing group onpara position like carboxylic acid (see Figure 2, compounds $\mathbf{2 a}$ and $\mathbf{2 i}$ ). When both methyl and hydrogen were used as the substituent, rather than using phenyl, aromaticities of both rings have remained almost same (Table 1, compounds $\mathbf{2 b}, \mathbf{2 c}$ ). Phenyl groups on the left side of both rings were changed with methyl group and we observed that pyridazinone and pyrazole have gained more aromatic character $(-2.8 \rightarrow$ $-3.2 \mathrm{ppm}, \triangle \mathrm{FIPC}-\mathrm{NICS}=-0.4 \mathrm{ppm}$ for pyridazine; $-6.8 \rightarrow-7.1 \mathrm{ppm} \Delta$ FIPC-NICS $=-0.3 \mathrm{ppm}$ for pyrazole) (Table 1, 2o). This small increase of aromaticity might be explained as follows: any $\mathrm{sp}^{2}$-hybridized functional group attached to pyridazinone or pyrazole decreases the contribution of delocalization through the rings. Either methyl group does not disturb delocalization of pyridazine and pyrazole or it gives contribution to aromaticity of the rings.

We have altered carboxylic acid into different functional groups in order to understand the effect of substituent attached to the phenyl ring. Carboxylic acid derivatives such as methyl urea (2d), amide (2f), ester (2g) and (2h), and acyl chloride (2k) were therefore investigated (Figure 3 ).

While aromaticity of heterocyclic rings for $\mathbf{2 c}$ was observed as -2.8 and $-6.8 \mathrm{ppm}$, same indexes for $\mathbf{2 d}$ were observed as -2.8 and $-7.4 \mathrm{ppm}$ (Table 1 ), respectively. Amide group (for $\mathbf{2 d}$ ) is more delocalized with carbonyl group than carboxylic acid and delocalization of benzene ring with amide group is less than the delocalization of carboxylic acid. The aromatic character of pyrazole ring rises due to this. Measuring the aromaticity of these pyridazinones shows that aromaticity of fiveand six-membered rings does not strictly depend on the substituents of para position of benzene ring attached to pyrazole.
Martinez et al. have described that aromaticity of heterocyclic ring such as pyrrole, thiophene and furan decreases dramatically when they are fused to benzene. ${ }^{23}$ However, considering all values, we have observed that aromaticity of pyridazinone ring was amenable to the aromaticity of pyrazole and vice versa. Broadly speaking, the increment of aromaticity of pyridazinone depends on increasing of aromaticity of pyrazole and vice versa. Nonaromatic form of pyridazinone decreases the aromaticity of pyrazole unit (Table $1,2 n$ ).

HOMA values indicate that aromaticity of pyridazine rings increase when attached to methyl group (Table $1, \mathbf{2 b})$ which is in good agreement with NICS values. However, in the case of methyl, hydrogen and phenyl ring, HOMA aromaticity of six-membered ring (Table 1, 2c, 2a) decreased. HOMA value of $\mathbf{2 0}, 0.4327$ for pyridazine, is more than that of $\mathbf{2 a}, \mathbf{2} \mathbf{b}$ or $\mathbf{2 c}$ in which there is no phenyl group attached to the ring. It means that electron-donating group affects HOMA and NICS aromaticity positively. When aromaticity of pyridazinone ring decreased, HOMA value of that ring decreased, as well (Table 1, 2n). FIPC-NICS and HOMA values for 2n are -1.4 and 0.078 , respectively. Same issue was observed for $\mathbf{2 p}$ in which FIPC-NICS and HOMA values were -1.0 and -0.099 , respectively.

\subsection{Aromaticity of pyrazolopyridazines}

For substituted pyrazolopyridazine, functional groups such as phenyl, amine, hydrogen and methyl groups were selected ${ }^{19,24}$ and the structures of these derivatives are shown in Figure 4.

HOMA values (Table 1) of all pyrazolopyridazines are higher than pyrazolopyridazinones, as expected. Pyridazine skeletons have more delocalization character than that of pyridazinone. In addition, HOMA 


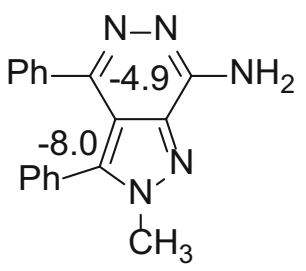

21

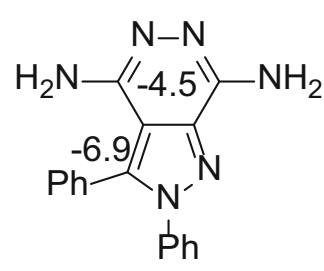

$2 \mathrm{~m}$

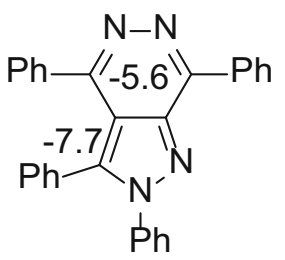

$2 \mathbf{r}$

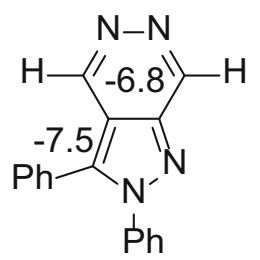

$2 s$

Figure 4. A few pyrazolopyridazine derivativess. The values refer to FIPC-NICS.

Table 2. Delocalization Contribution of C6-C9 of Pyridazines.

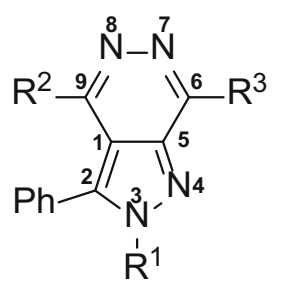

\begin{tabular}{lccccccc}
\hline Comp. No. & $\mathbf{R}^{1}$ & $\mathbf{R}^{2}$ & $\mathbf{R}^{3}$ & paraDI (C6-C9) & paraDI (C1-N7) & paraDI (C5-N8) & FIPC-NICS Pyridazine \\
\hline $\mathbf{2 l}$ & $\mathrm{Me}$ & $\mathrm{Ph}$ & $\mathrm{NH}_{2}$ & 0.0624 & 0.0430 & 0.0472 & -4.9 \\
$\mathbf{2 m}$ & $\mathrm{Ph}$ & $\mathrm{NH}_{2}$ & $\mathrm{NH}_{2}$ & 0.0561 & 0.0421 & 0.0444 & -4.5 \\
$\mathbf{2 s}$ & $\mathrm{Ph}$ & $\mathrm{H}$ & $\mathrm{H}$ & $\mathbf{0 . 0 8 5 4}$ & 0.0496 & 0.0503 & $-\mathbf{6 . 8}$ \\
\hline
\end{tabular}

Values in bold indicate the most contribution of atoms and the most FIPC-NICS

aromaticity of these pyridazine rings have been compared. HOMA value of these rings are within the range of $0.6963-0.7740$. The highest HOMA value points to the pyridazine ring of $\mathbf{2 s}$ in which there is no substituent on the six-membered ring. Attachment of two phenyl groups on pyridazine ring reduced HOMA value from 0.7740 (2s) to 0.7307 (2r). These two rings might affect internal delocalization. While replacement of phenyl group with $\mathrm{NH}_{2}$ (2I) increased HOMA value, replacement of phenyl with $\mathrm{OH}(\mathbf{2 e})$ decreased HOMA value. These might be due to differences between electron donating ability of oxygen and nitrogen on the aromatic ring.

Pyridazine units of $\mathbf{2 1}, \mathbf{2 m}, \mathbf{2 r}$ and $\mathbf{2 s}$ have stronger aromaticity than the above-mentioned pyridazinones since pyridazines have more delocalization character. Pyridazinones do not produce delocalization effectively due to the carbonyl group while $\mathbf{2 l}, \mathbf{2 m}, \mathbf{2 r}$ and $\mathbf{2 s}$ show ful delocalization of $\pi$ electrons, resulting in higher aromaticity and stability. Thus, pyrazole units of $\mathbf{2 l}, \mathbf{2 m}, \mathbf{2 r}$ and $2 \mathrm{~s}$ exhibit more aromatic character. It means that the increased aromaticity of pyridazine ring affects aromaticity of the pyrazole ring progressively. Aromaticity of pyridazine ring of $\mathbf{2 l}$ is higher than that of $\mathbf{2 m}$. It might be because of two identical amine groups attached to the pyridazine ring of $\mathbf{2} \mathbf{m}$, which can affect each other adversely. The most aromatic character that we have observed for pyridazine belongs to $2 \mathrm{~s}$ (pyridazine: -6.8 , pyrazole: -7.5 ppm) (Table 1). To figure out the reason(s) for these differences in terms of aromaticity between $\mathbf{2 l}$, $\mathbf{2 m}$ and $\mathbf{2 s}$, we have calculated delocalization contribution of para position of two centers which are C6 and C9 (Table 2).

Para delocalization index collects information for aromaticity of six-membered rings by calculating contribution of atoms, which are at para position of the aromatic rings. ${ }^{5 f}$ Therefore, we have calculated some of para-delocalized atoms of relevant rings that have different substituents which can affect each other. These atoms are C6-C9 and we have explored that there is a common ground between FIPC-NICS and delocalization contribution of C6-C9 atoms in a positive way. FIPC-NICS for pyridazine ring increases as a result of an increase in delocalization contribution of C6-C9. For instance, the most significant contribution of para position belongs to $\mathbf{2 s}$, while the most important aromaticity characteristics of pyridazine belong to $2 \mathbf{s}$, which might be because of not having any group affecting delocalization negatively. Since two identical amine groups are attached to pyridazine of $\mathbf{2} \mathbf{m}$, the contribution and aromaticity of both C6-C9 decrease. The cause of this situation can be easily seen by comparing the contribution of $\mathbf{2 m}$ with the contribution of $\mathbf{2} \mathbf{l}$ which has only one amine group. The contribution of delocalization parameters such as $\mathrm{C} 1-\mathrm{N} 7$ and $\mathrm{C} 5-\mathrm{N} 8$ is not very significant, since they do not have excessive contribution. 


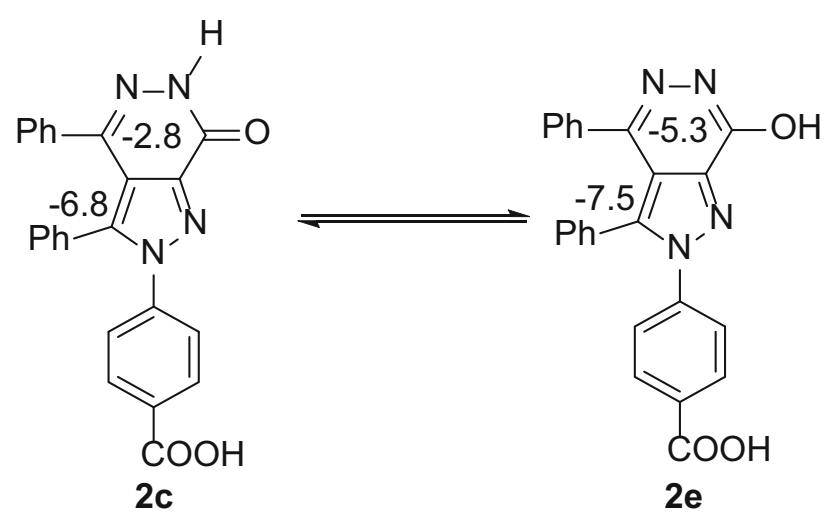

Scheme 1. Tautomerization of $\mathbf{2 c}$. The values refer to FIPC-NICS.

Finally, we have brought into view that there might be a relationship between aromaticity and delocalization contribution of atoms on para position of aromatic ring that have nitrogen atom.

HOMA values of $\mathbf{2 l}, \mathbf{2} \mathbf{m}$ and $\mathbf{2 r}$ are in good agreement with FIPC-NICS and PDI values. We have observed that increasing of FIPC-NICS are resulting in increasing of HOMA. However, there is a discrepancy between FIPCNICS and HOMA values of $\mathbf{2 r}$ when compared with $\mathbf{2 l}$, $\mathbf{2 m}$ and $\mathbf{2 s}$. This issue might be because of two identical phenyl rings attached to the pyridazine ring of $\mathbf{2 r}$ in which these phenyl rings might disturb the planarity of the pyridazine ring a little resulting in unexpected decrease in the value of HOMA.

\subsection{Depicting dominant tautomer form of some pyrazolopyridazinones}

Tautomerization is a vital phenomenon and should be discussed in detail. ${ }^{24 a-d}$ After reviewing the studies related to pyrazolopyridazinone derivatives in the literature, we have concluded that some tautomer form of $\mathbf{2 c}, \mathbf{2 m}$, and $\mathbf{2 n}$ might exist theoretically. When we analyzed the data of NMR spectra of $\mathbf{2 c}$ or $\mathbf{2 e}$ (see Supplementary Information), we could not find more lines than expected. This means that there is just one tautomer form in the solution, but it is difficult to judge which one is more dominant. Same issues were mentioned by Kasimogulları and Arslan ${ }^{25}$ and Bildirici et $a l .,{ }^{25 \mathrm{~b}}$ for the same derivatives. We have proposed that there is tautomerization in these compounds. Therefore, we have collected some data via computation to find out which tautomer form might be the dominant one in these molecules. We have chosen $\mathbf{2 c}$ and $\mathbf{2 m}$; first, we have checked $\mathbf{2 c}$ and its tautomer form $\mathbf{2 e}$ (Scheme 1).

Outcome of theoretical calculations showed that aromaticity of pyridazine ring of $\mathbf{2} \mathbf{e}$ is higher than that of 2c. We calculated distances and bond orders of the two tautomers using three different methods (Table 3).

During tautomerization, it was observed that some distances such as $\mathrm{x}, \mathrm{t}, \mathrm{w}$ have become shorter (Table 3 ). Bond shortening means the number of $\pi$ electrons is increasing and double bond features are occurring more than before. Mayer bond order (MBO), ${ }^{26}$ Fuzzy

Table 3. Bond orders of $2 \mathrm{c}$ and $2 \mathrm{e}$ by different methods.

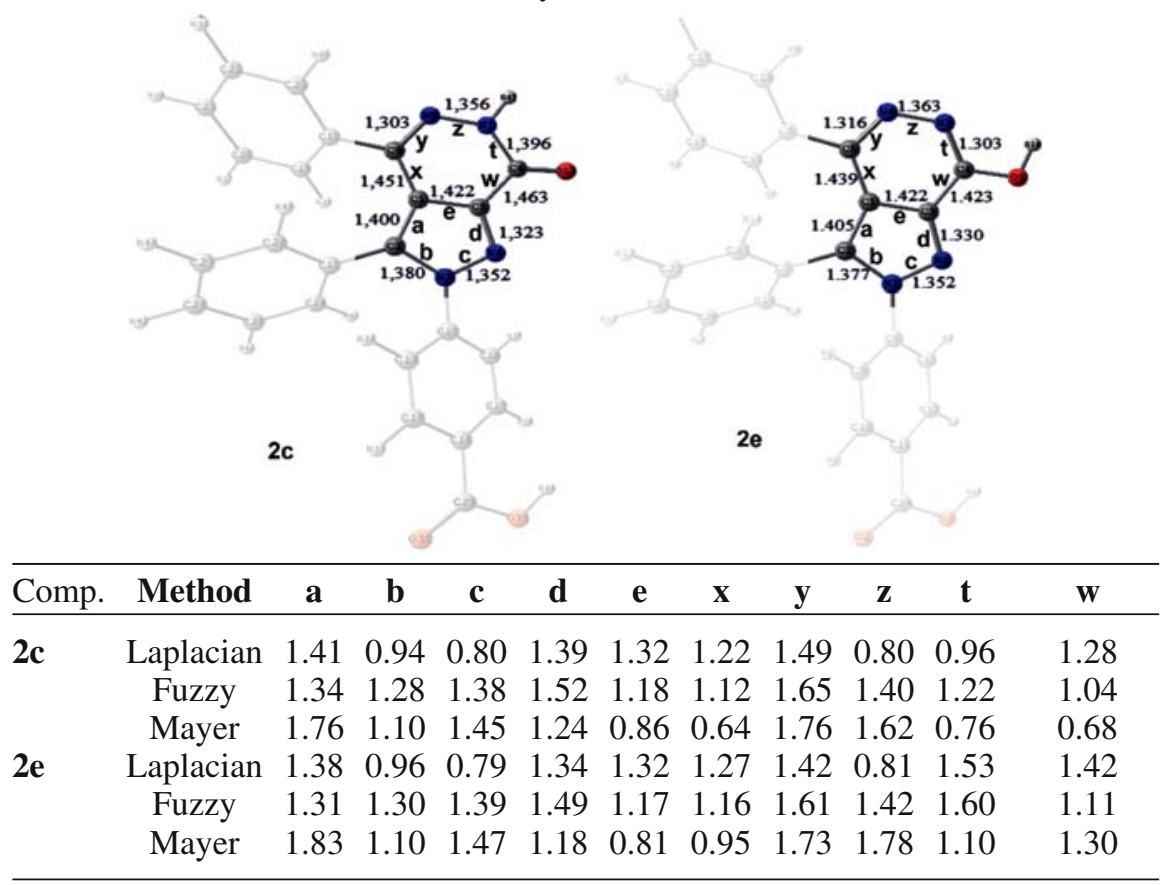

The values on figures refer to bond distances. 

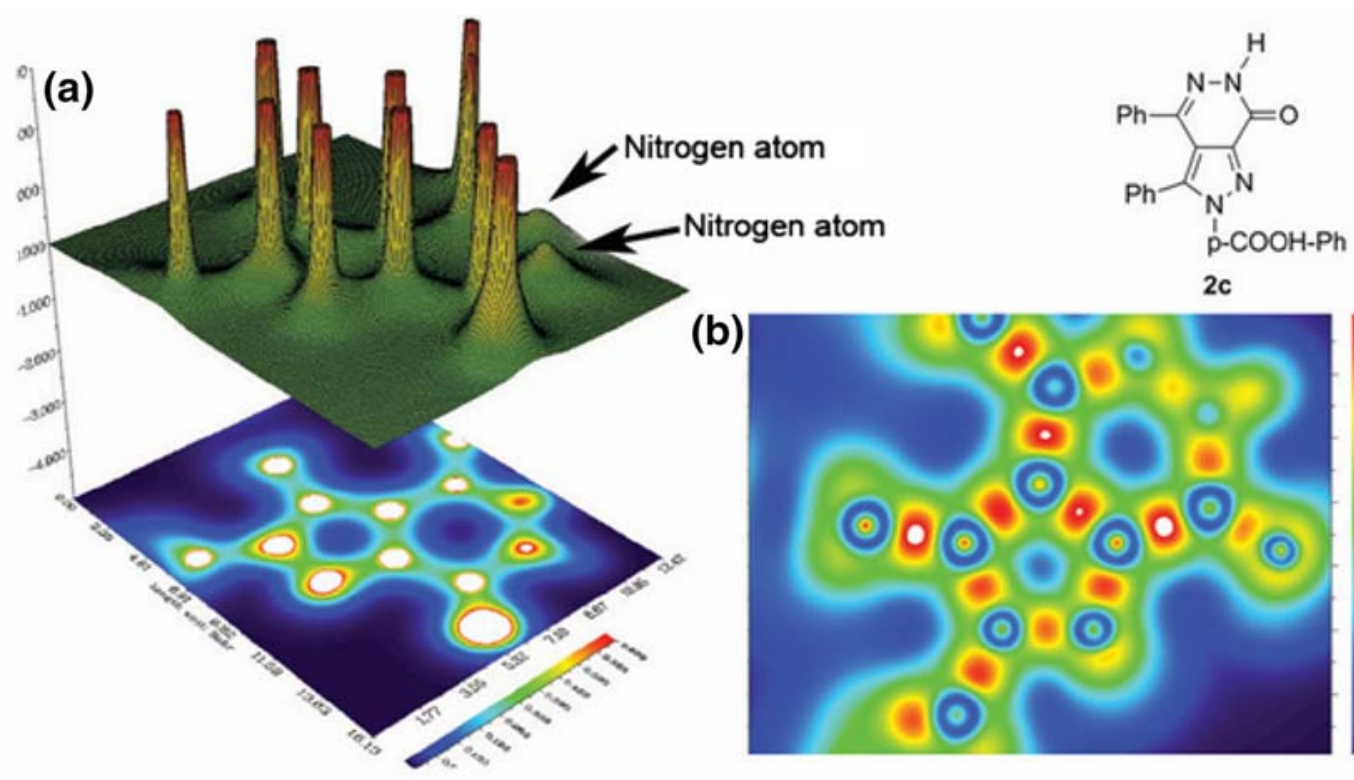

(b)
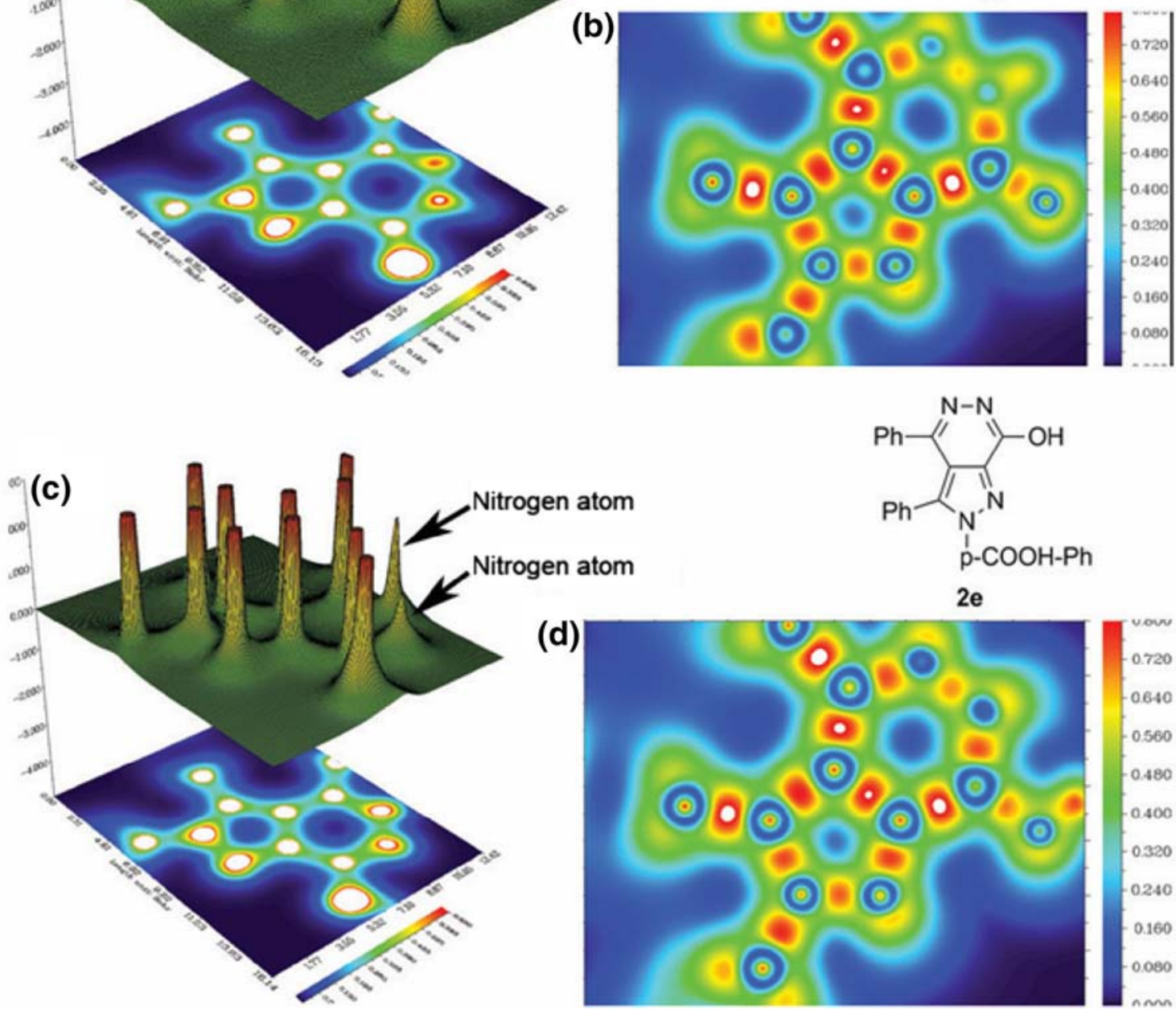

2e

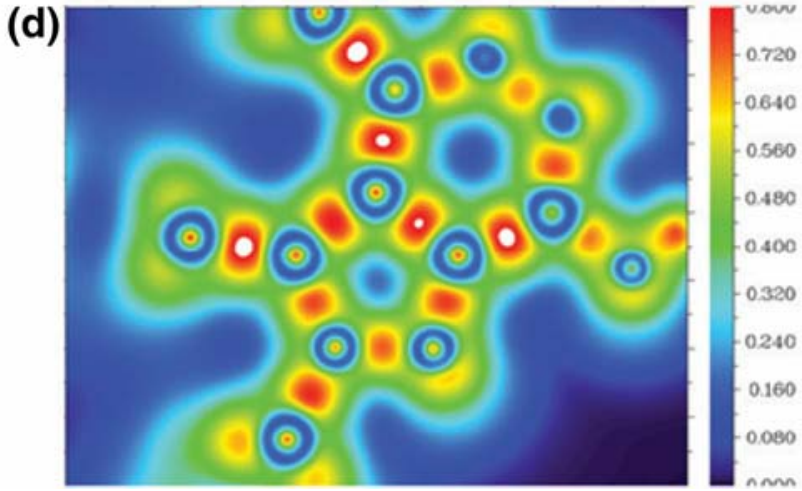

Figure 5. Electron density and LOL maps of 2c and 2e. a) Electron density with shaded surface maps with projection of $2 \mathrm{c}$; b) localized orbital locator (LOL) of $2 \mathrm{c}$ (for clarity benzene rings were omitted) c) electron density with shaded surface map with projection for $\mathbf{2 e}$; d) localized orbital locator (LOL) of $\mathbf{2 e}$ (for clarity benzene rings were omitted).

Bond Order, ${ }^{27}$ Laplacian bond order $^{28}$ were used to see how bond orders are altered. We have observed that Fuzzy bond order method has given more accurate results, since the rest of the methods have shown some deviations for both heterocyclic rings. It might be said that bond order of pyrazolopyridazine-type molecules, which have more than one nitrogen atom, might be observed more accurately by Fuzzy method. Energy differences between $\mathbf{2 c}$ and $\mathbf{2 e}$ were calculated (B3LYP/6-311 + G(d,p)) and it was seen that $2 \mathrm{e}$ was more stable than $2 \mathrm{c}$ by about $13.68 \mathrm{kcal} / \mathrm{mol}$. This information shows which form is more dominant. The central property on which the localization descriptor LOL is built is the kinetic-energy density. The kinetic energy plays a major role in the description of chemical bond, since the driving force of covalent bonding is a lowering of the quantum kinetic-energy density by orbital sharing. ${ }^{29}$ To observe covalent bond character and localization of electron density of bonds, we calculated and visualized electron density and localized orbital locator $(\mathrm{LOL})^{29}$ of $\mathbf{2 c}$ and $\mathbf{2 e}$. The results gained by the calculation and visualization are shown in Figure 5. In addition, for both tautomer forms, HOMO-LUMO orbitals were plotted to see which orbital gives more contribution to these frontier orbitals (Figure S1 in Supporting Information). 


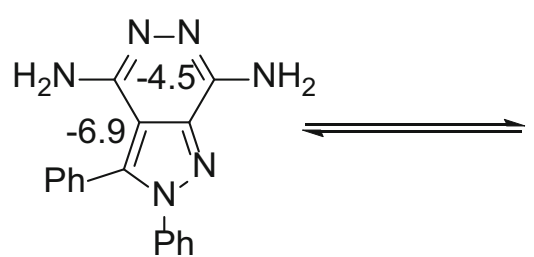

$2 \mathrm{~m}$

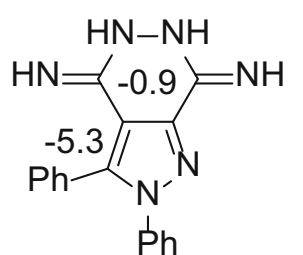

$2 p$
Scheme 2. Tautomerization of $\mathbf{2 m}$. The values refer to FIPC-NICS.

Electron density on nitrogen atoms (red and blue colored region) of $\mathbf{2 c}$ is lower than that of $\mathbf{2 e}$ (Figure 5, a and c) in the electron density map and this might be because of poor electron delocalization, which results in decreasing aromaticity character. Furthermore, it can be seen that the localized orbital map of $2 \mathbf{e}$ between two nitrogen atoms of pyridazine has more covalent region (red and reddish-colored region between blue circles) than that of 2c (Figure 5, b and d). These maps show that if any delocalization occurs, it affects the electron density of the ring, resulting in increased aromaticity and electron density. All of these data and visualized maps mentioned above have indicated that tautomeric form of 2e might be more dominant. Furthermore, HOMA value of $2 \mathbf{e}$ for six-membered ring is more than that of $\mathbf{2 c}$. This means that $\mathbf{2 e}$ might be more favorable.

Another tautomeric form which we wanted to calculate is $\mathbf{2 m}$ and its tautomer form, $\mathbf{2 p}$ (Scheme 2). Tautomerization between $\mathbf{2 m}$ and $\mathbf{2 p}$ was calculated and it was observed that aromaticity of pyridazine unit decreased with formation of $\mathbf{2 p}$ and pyridazine ring of $\mathbf{2 p}$ can be mentioned as non-aromatic heterocyclic ring (FIPC-NICS $=-1 \mathrm{ppm})$. Elongation and/or shortening of bond distances and altering of bond orders were calculated by using three different methods. The results of these calculations are given in Table 4.

The calculated bond distances have indicated that when pyridazine ring is fully delocalized $(\mathbf{2 m}), \mathrm{x}, \mathrm{y}$, $\mathrm{z}, \mathrm{t}$ and $\mathrm{w}$ distances are shortened, which means that pyridazine ring gains more double bond character. Bond orders of both forms were compared and we have seen that bond orders of $\mathrm{x}, \mathrm{y}, \mathrm{z}, \mathrm{t}$ and $\mathrm{w}$ of $\mathbf{2} \mathbf{m}$ have increased. Once again, we have seen that the best method that can be used for this type of heterocyclic system might be the Fuzzy method to calculate bond orders. We have also created and visualized some electron density maps for $\mathbf{2 m}$ and $\mathbf{2 p}$ to observe how electron density is altered when tautomerization occurs (Figure 6).

It can be easily seen that $\mathbf{2} \mathbf{m}$ has more electron density on nitrogen atoms in the pyridazine ring (Figure 6 , a and c). This point indicates that electron delocalization of pyridazine ring of $\mathbf{2} \mathbf{m}$ is effectively higher because of full conjugation. Moreover, when we analyzed the LOL maps of $\mathbf{2} \mathbf{m}$ and $\mathbf{2 p}$, we have explored that electron density of covalent bonds of $\mathbf{2 m}$ (red and reddish colored regions, Figure $6, \mathrm{~b}$ and d), which was increased. Finally, it might be said that if any tautomerization occurs between $\mathbf{2 m}$ and $\mathbf{2 p}$, then $\mathbf{2 m}$ will be more dominant due to all parameters mentioned above.

Table 4. Bond orders of $\mathbf{2 m}$ and $2 \mathbf{p}$ calculated by three different methods.

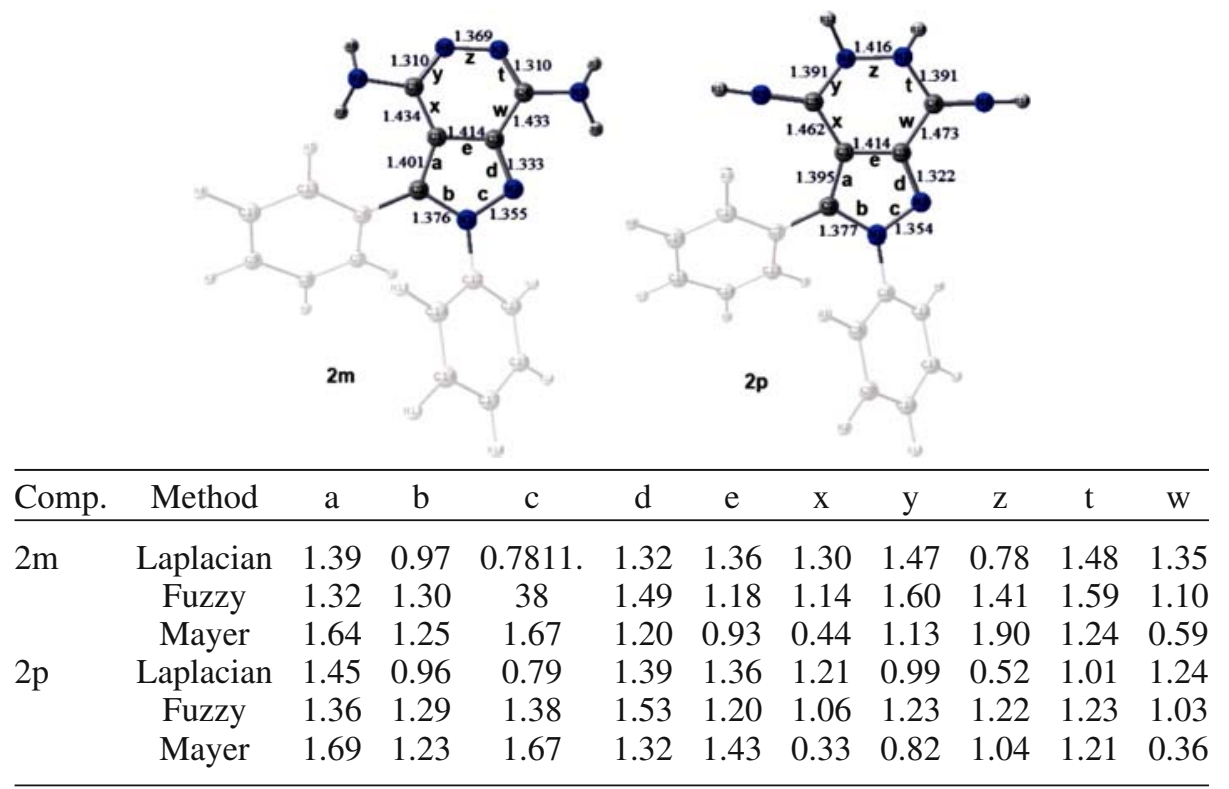

The values on figures refer to bond distances. 

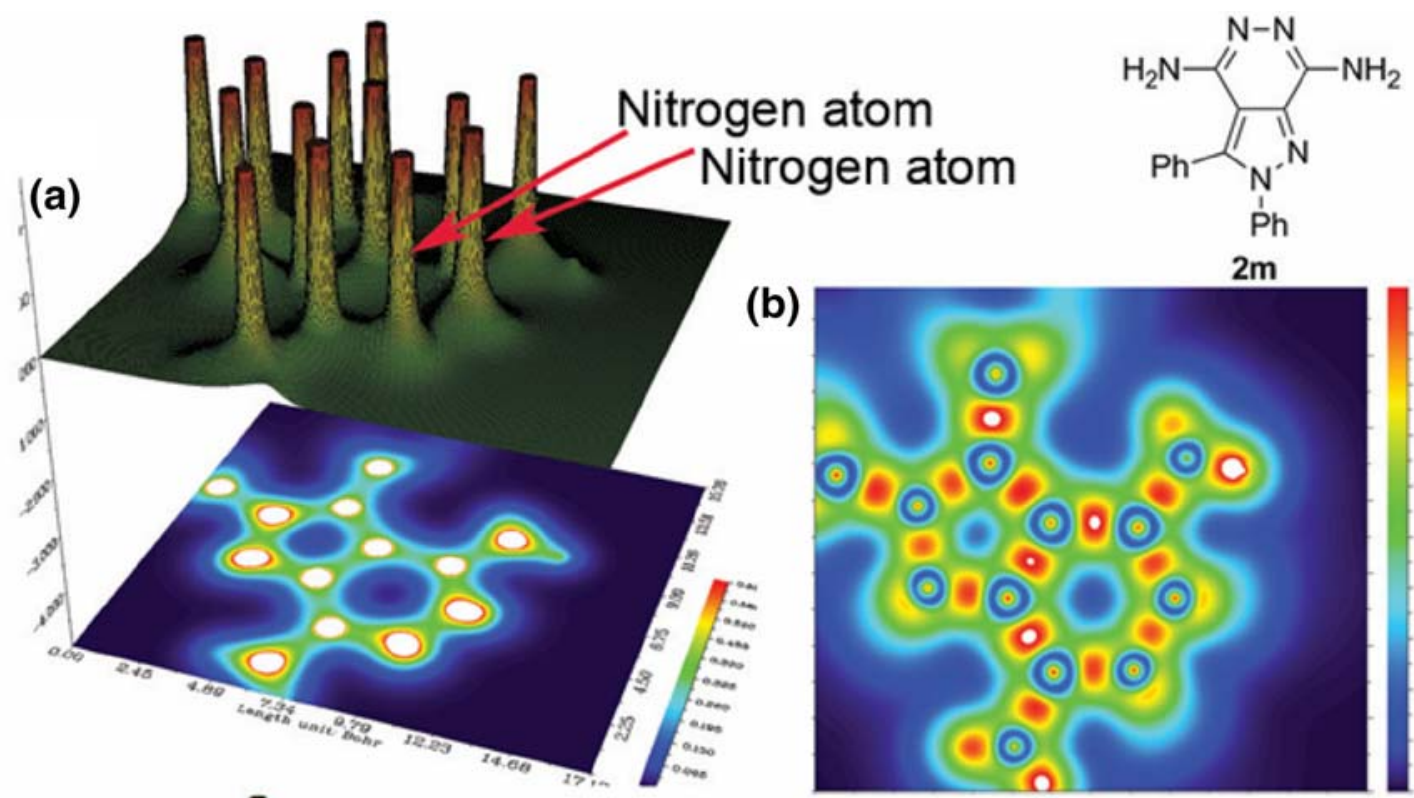

(b)
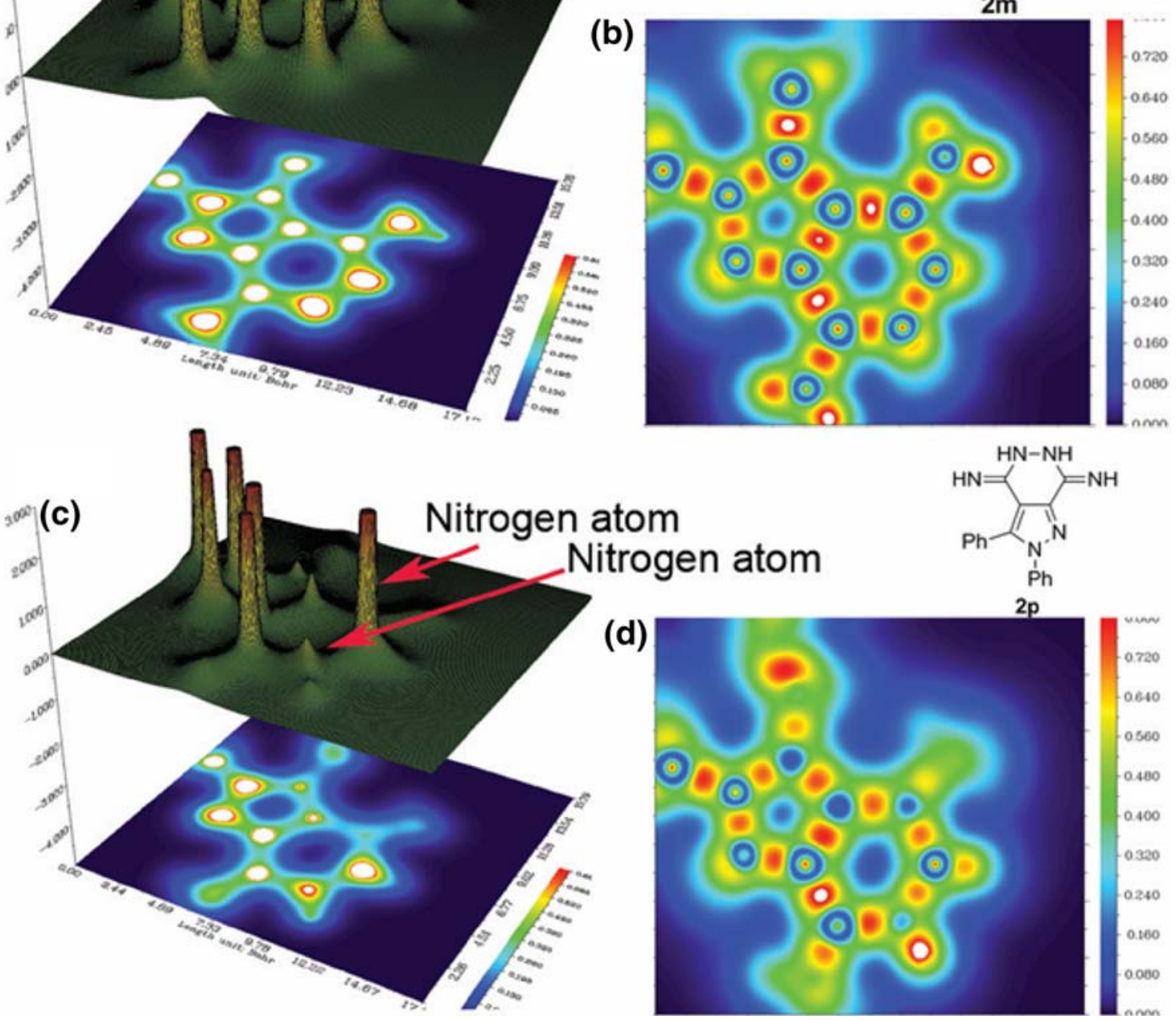

(d)

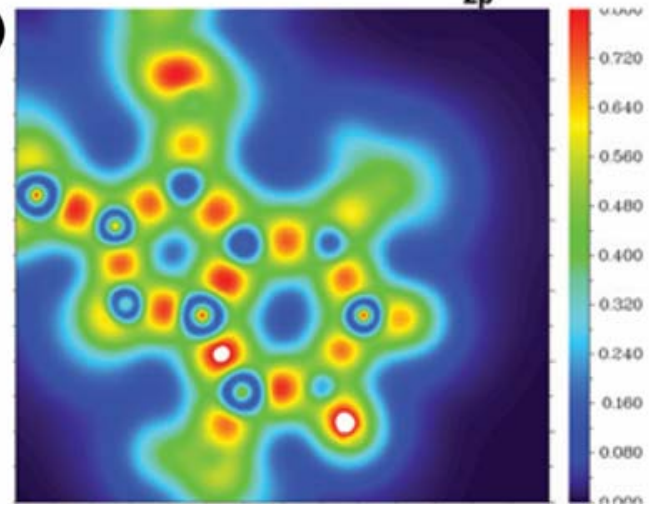

Figure 6. Electron density and LOL maps of $\mathbf{2 m}$ and $\mathbf{2 p}$. a) Electron density with shaded surface map with projection of $\mathbf{2 m}$; b) localized orbital locator (LOL) of $\mathbf{2 m}$ (for clarity benzene rings are omitted). c) electron density with shaded surface map with projection for $\mathbf{2 p}$; d) localized orbital locator (LOL) of $\mathbf{2 p}$ (for clarity benzene rings were omitted).

In addition, for both the tautomer forms, HOMO-LUMO orbitals were plotted to see which orbital gives more contribution to these frontier orbitals (Figure S2 in Supporting Information). In addition, HOMA value of $\mathbf{2 p}$ indicates that this ring might be nonaromatic or antiaromatic which is not favorable, as can be seen in the LOL map of $\mathbf{2 p}$ (Figure 6, c and d).

\section{Conclusions}

We have selected some pyrazolopyridazin(on)es with different substituents which are reported in the literature.
These molecules were subjected to some theoretical calculations and we have collected data about aromaticity of these molecules. NICS(0), NICS(1), NICSzz(1), FIPC-NICS and HOMA were used to compare the data obtained to enlighten the aromaticity character of pyrazolopyridazin(on)es. It was found that the most accurate aromatic character for pyrazolopyridazin(on)es can be calculated by using FIPC-NICS. Furthermore, we have calculated bond orders for four different tautomeric forms and we have shown that Fuzzy method might be the best method to calculate bond orders of pyrazolopyridazin(on)e-type molecules. Possibility of 
tautomeric forms was studied. According to the bond orders, bond distances, aromaticity parameters and visualized electron density maps such as LOL, it is revealed that which of tautomeric form might be more dominant. In addition, in this study, we have collected a lot of information about aromaticity of pyrazolopyridazin(on)es. For future studies, this study might be a useful reference for these types of molecules.

\section{Supplementary Information (SI)}

Supplementary Information (HOMOs and LUMOs for $\mathbf{2 c}$, $\mathbf{2 e}, \mathbf{2 m}$ and $\mathbf{2 p}$, Coordinates for compounds and NMP spectra for synthesized compounds) is available at www.ias.ac.in/ chemsci.

\section{Acknowledgements}

N. M. thanks Gül Mengeş for preparing of graphical abstract and Dr. Çağatay Dengiz for proof reading. Authors thank Yuzuncu Yil University Scientific Research Board (Grant No: 2014-ECZ-B170).

\section{References}

1. Ivashchenko A, Lavrovsky Y, Malyarchuk S, Okun I, Savchuk N, Tkachenko S, Khvat A and Ivashchenko A 2013 Heterocyclic inhibitors of an hh-signal cascade, medicinal compositions based thereon and methods for treating diseases caused by the aberrant activity of an hh-signal system U. S. Patent 8,486,945

2. Myatt J M, Healy M P, Bravi G S, Billington A, Johnson C N, Matthews K L, Jandu K S, Meng W, Hersey A, Livermore D G, Douault C B, Witherington J, Bit R A, Rowedder J E, Brown J D and Clayton N M 2010 Pyrazolopyridazine alpha-2-delta-1 ligands for the treatment of neuropathic pain Bioorg. Med. Chem. Lett. 204683

3. Cesari N, Biancalani C, Vergelli C, Dal Piaz V, Graziano A, Biagini P, Ghelardini C, Galeotti N and Giovannoni P 2006 Arylpiperazinylalkylpyridazinones and Analogues as potent and orally active antinociceptive agents: Synthesis and studies on mechanism of action J. Med. Chem. 497826

4. Feixas F, Matito E, Poater J and Sola M 2008 On the performance of some aromaticity indices: A critical assessment using a test set J. Compt. Chem. 291543

5. (a) Schleyer P 2001 Introduction: Aromaticity Chem. Rev. 101 1115; (b) Randric M 2003 Aromaticity of Polycyclic Conjugated Hydrocarbons Chem. Rev.103 3449; (c) Katritzky A R, Jug K and Oniciu D C 2001 Quantitative Measures of Aromaticity for Mono-, Bi-, and Tricyclic Penta- and Hexaatomic Heteroaromatic Ring Systems and Their Interrelationships, Chem. Rev. 101 1421; (d) Kruszewiski J and Krygowski T M 1972 Definition of aromaticity on the harmonic oscillator model Tetrahedron Lett. 13 3839; (e) Poater J, Fradera X, Duran M and Sola M 2003 The Delocalization Index As An Electronic Aromaticity Criterion: Application To A Series Of Planar Polycyclic Aromatic Hydrocarbons
Chem. Eur. J. 9 400; (f) Güell M, Matito E, Luis J M and Sola M 2006 Analysis of Electron Delocalization in Aromatic Systems: Individual Molecular Orbital Contributions to Para-Delocalization Indexes (PDI) J. Phys. Chem. A110 11569; (g) Krygowski T M and Cyranski M K 2001 Structural Aspects of Aromaticity Chem. Rev. 1011385

6. Balaban A T, Oniciu D C and Katritzky A R 2004 Aromaticity as a cornerstone heterocyclic chemistry Chem. Rev. 1042777

7. Fowler P W, Lillington M and Olson L P 2007 Aromaticity, pi-electron delocalization, and ring currents Pure Appl. Chem. 79969

8. Proft F and Geerlings P 2001 Conceptual and computational DFT in study of aromaticity Chem. Rev. 1011451

9. Klod S and Kleinpeter E J 2001 Ab initio calculation of the anisotropy effect of multiple bonds and the ring current effect of arenes-application in conformational and configurational analysis Chem. Soc. Perkin Trans. 24 1893

10. Torres-Vega J J, Vasquez-Espinal A, Caballero J, Valenzuela M L, Alvarez-Thon L, Osorio E and Tiznado W 2014 Minimizing the Risk of Reporting False Aromaticity and Antiaromaticity in Inorganic Heterocycles Following Magnetic Criteria Inorg. Chem. 533579

11. Schleyer P R, Maerker C, Dransfeld A, Jiao H and Hommes N J R E 1996 Nucleus-independent chemical shift: A simple and efficient aromaticity probe $J$. Am. Chem. Soc. 1186317

12. (a) Gaussian 09, Revision C.01, Frisch M J et al.; (b) Miao S, Brombosz S M, Schleyer P R, Wu J I, Barlow S, Marder S R, Hardcastle K I and Bunz U H F 2008 Are N,N-dihydrodiazatetracene derivatives antiaromatic J. Am. Chem. Soc. 130 7339; (c) Sanchez-Sanz G, Alkorta I, Trujillo C and Elguero J 2012 A theoretical NMR study of the structure of benzynes and some of their carbocyclic and heterocyclic analogs Tetrahedron 68 6548; (d) Mills N S and Lagostera K B 2007 Summation of nucleus independent chemical shifts as a measure of aromaticity J. Org. Chem. 729163

13. Priyakumar U D and Sastry G N 2003 Measures to evaluate heteroaromaticity and their limitations: Story of skeletally substituted benzenes J. Chem. Sci. 11549

14. Purkayastha $S$ and Bhattacharyya $P 2016$ Does oligomerization in fused thiophene affect reactivity and aromaticity J. Chem. Sci. 128311

15. Sen R and Bhattacharyya S 1986 Semi-empirical calculation of static molecular polarizability using CHFT: Some benzene derivatives and aromatic heterocycles $J$. Chem. Sci. 96281

16. NICSiso $(0)$ values of pyridazinone unit for compound 2b: GIAO HF/631 G +(d): -0.93; DFT/B3LYP 6311 $\mathrm{G}+(\mathrm{d}, \mathrm{p}):-1.54 ;$ DFT/B3LYP $6311 \mathrm{G}+(\mathrm{d}):-1.55$; DFT/B3LYP G ++ (d, p): -1.87

17. $\mathrm{Lu} \mathrm{T}$ and Chen $\mathrm{F} 2012$ Multiwfn: A multifunctional wavefunction analyzer J. Comp. Chem. 33580

18. Lu T and Chen F 2012 Quantitative analysis of molecular surface based on improved Marching Tetrahedra algorithm J. Mol. Graphics Modell. 38314

19. Akbas E and Berber İ 2005 Antibacterial and antifungal activities of new pyrazolo[3,4-d]pyridazin derivatives Eur. J. Med. Chem. 40401 
20. Matiichuk V S, Potopnyk M A and Obushak N D 2008 Molecular design of pyrazolo[3,4-d]pyridazines Russ. J. Org. Chem. 441352

21. Bildirici İ, Şener A, Atalan E, Battal A and Genç H 2009 Synthesis and antimicrobial screening of N-(1-methyl-1H-pyrazole-4-carbonyl)-thiourea derivatives Med. Chem. Res. 18327

22. Cyranski M K, Krygowski T M, Katritzky A R and Schleyer P R 2002 To what extent can aromaticity be defined uniquely J. Org. Chem. 671333

23. Martinez A, Vazquez M V, Carreon-Macedo J L, Sansores L E and Salcedo R, 2003 Benzene fused fivemembered heterocycles. A theoretical approach Tetrahedron 596415

24. (a) Dutta P, Saikia M, Das R J and Borah R 2014 Investigation of keto-enol tautomers during the synthesis of aryl-bis (2-hydroxy-1-naphthyl)methanes J. Chem. Sci. 126 1629; (b) Kalia S, Sharma A and Kaith B S 2007 J. Chem. Sci. 119 2007; (d) El-Sakka S S, Soliman M H and Abdullah R S 2014 Behaviour of 4-[4-methoxy- 3-methylphenyl]-4-oxobutenoic acid towards nitrogencontaining nucleophiles J. Chem. Sci. 1261883

25. (a) Kasimoğulları R and Arslan B S 2010 Synthesis and characterization of some pyrazole derivatives of 1,5diphenyl-1H-pyrazole-3,4-dicarboxylic acid J. Heterocycl. Chem. 47 1040; (b) Bildirici İ, Şener A and Tozlu I 2007 Further derivatives of 4-benzoyl-1,5-diphenyl1H-pyrazole-3-carboxylic acid and their antibacterial activities Med. Chem. Res. 16418

26. Mayer I 1983 Charge, bond order and valence in the AB initio SCF theory Chem. Phys Lett. 97270

27. Mayer I and Salvador P 2004 Overlap populations, bond orders and valances for fuzzy atoms Chem. Phys. Lett. 383368

28. Lu T and Chen F 2013 Bond order analysis based on the laplacian of electron density in fuzzy overlap space $J$. Phys. Chem. A 1173100

29. Jacobsen H 2008 Localized-orbital locator (LOL) profiles of chemical bonding Can. J. Chem. 86 695 